BROCAR, 30 (2006) 37-63

\title{
LOS VECINOS ESPAÑOLES ANTE LOS INDIOS DE FRONTERA: EL GRAN NORTE DE NUEVA ESPAÑA
}

\author{
Alfredo Jiménez Núñez \\ Universidad de Sevilla
}

\begin{abstract}
RESUMEN: Se define como Gran Norte los territorios situados más allá del Valle de México que durante siglos estuvieron bajo jurisdicción española y se consideraron frontera en el sentido amplio del término. La atención se centra en los vecinos, o población civil, y en los efectos que sobre sus personas y bienes produjo una guerra centenaria con el indio. Ante la persistencia en ciertas regiones de factores ecológicos, se sugiere que el estudio de las fronteras coloniales en las Américas tenga en cuenta los antecedentes y consecuentes (fronteras prehispánica y republicana) así como la cultura o cosmovisión de la sociedad dominante. Los testimonios utilizados son transcripciones literales de documentos del Archivo General de Indias de Sevilla.
\end{abstract}

Palabras clave: Norte de Nueva España, vecinos e indios bárbaros, guerra, fronteras ecológicas, cosmovisión, etnohistoria.

ABSTRACT: The Great North is defined as the territories beyond the Valley of Mexico over which Spain held sway for centuries and were considered a frontier land in its wide sense. The focus is on the vecinos, or civil population, and the effects produced on their persons and properties by a centennial war. It is suggested that the best full approach to colonial frontiers in the Americas should include the consideration of what happened before and after the colonial period (pre-Hispanic and republican frontiers). This argument is based on the persistence of crucial ecological factors in certain regions. The culture or worldview of the dominant society is also significant. The testimonies presented are literal transcriptions of documents from the Archivo General de Indias in Seville.

Keywords: Northern New Spain, settlers and barbarian Indians, warfare, ecological frontiers, woldview, ethnohistory.

Considero en el presente ensayo la actitud y conducta de los vecinos españoles (criollos o europeos) en relación con la población indígena de la frontera norte de Nueva España. El acercamiento a cualquiera de los grandes temas de las fronteras coloniales americanas resultará siempre más fértil en el marco continental y 
en conexión con los períodos prehispánico y republicano. Esto último es así porque las grandes fronteras traspasaron las barreras del tiempo histórico por efecto de factores ecológicos permanentes. Desde esta doble perspectiva de espacio y tiempo es posible encontrar respuestas objetivas a cuestiones como semejanzas y diferencias, éxitos y fracasos, brevedad o larga duración. En esta ocasión, escucharemos a los españoles de la frontera norte del virreinato de México con especial atención a quienes no siendo militares ni misioneros, sino vecinos, se lamentaban por sí mismos o a través de las autoridades de los daños que los indios "bárbaros" causaban a sus personas y a su economía. En otras palabras, se trata de conocer el lado humano de una población instalada en un espacio de frontera de guerra. Sería muy interesante y legítimo escuchar también la voz de los indígenas sobre la presencia española en sus tierras, sus puntos de vista acerca de la guerra, su relato de los abusos sufridos durante generaciones. Pero ello sólo es posible en mínima proporción y a través de los propios españoles, especialmente los misioneros.

\section{Fronteras ecológicas y cosmovisiones}

Es obvia, aunque no siempre tenida en cuenta en los estudios monográficos, la influencia combinada de la naturaleza y de la cultura en los grandes procesos históricos. Los españoles observaron de inmediato diferencias entre los indios del Nuevo Mundo al calificar a unos como "civilizados" (aztecas, mayas, incas...) y a otros como "bárbaros". Los primeros pertenecían a una de las dos civilizaciones indígenas que se desarrollaron en las áreas conocidas por los arqueólogos como Mesoamérica y Andes Centrales. En medio había otros pueblos que no estaban organizados en estados ni tenían ciudades pero habían superado tiempo atrás el nivel tribal. Eran los señoríos o grandes cacicatos de América Central y parte de Colombia, pertenecientes a la América Intermedia. Fuera de la América Nuclear vivían los indios nómadas o seminómadas y los simples agricultores.

La expansión imperial de aztecas e incas se vio frenada por barreras naturales que resultaron insalvables a unas sociedades preindustriales que, no obstante, poseían la complejidad y eficiencia propias de la civilización: ciudades, estado, panteón y religión oficial, ejército profesional, nobleza, comerciantes, pueblo llano... Pero no todo fue un problema de tecnología en la expansión de las fronteras, al menos en Mesoamérica. Los territorios áridos al norte del Valle de México no ofrecían nada de interés a la economía de los aztecas. Sus habitantes bárbaros (chichimecas)' ni siquiera servían como cautivos de guerra ya que el sacrificio

1. El término más utilizado por los españoles para designar a los indígenas de la frontera fue el de bárbaros. Es la mejor traducción posible de chichimeca con el que los aztecas se referían a las poblaciones extrañas y ajenas a su mundo civilizado. Muy reciente, y lo mejor que se ha escrito con mucha diferencia sobre el tema, es Weber, D., Bárbaros. Spaniards and Their Savages in the Age of Enlightenment. Yale University Press. New Haven y Londres, 2005. Edición en español, Crítica. Barcelona, 2007. Sobre la visión de las autoridades ilustradas véase, por ejemplo, Jiménez Núñez, A., "El bárbaro en la mente y la voz del ilustrado: la frontera norte de Nueva España (s. XVIII)", en Bernabéu Albert, S. (coord.), El Gran Norte de México. CSIC. Madrid, [2009]. En prensa. 
ritual exigía sangre de guerreros nobles como alimento para los dioses encargados de la conservación del universo. El sistema cultural mesoamericano estaba basado en la simbiosis y complementariedad entre Tierras Altas (templadas) y Tierras Bajas (calientes); en el comercio de larga distancia y el tributo como aceptación del sometimiento político; en las relaciones entre iguales, incluso para hacerse la guerra. Nada de esto existía ni era posible al norte del Valle de México. Entre aztecas y chichimecas se abría un abismo no muy ancho -pues la distancia geográfica entre civilización y barbarie era corta- pero ciertamente muy profundo.

Los factores ecológicos limitaron también la expansión de los incas. El imperio se había hecho en pocas décadas demasiado grande para ser gobernado desde el ombligo del mundo, desde Cuzco. La máquina de guerra de los incas y su sistema de intendencia a base de rebaños de llamas y de tambos situados a lo largo de los caminos no estaban concebidos para penetrar en la selva amazónica o atravesar los desiertos del sur. Una cultura sumamente compleja en lo religioso y en lo administrativo no era funcional en absoluto más allá de los límites de su ecosistema. En resumen, los territorios al norte de los aztecas y los territorios más allá del Tawantinsuyu fueron márgenes o fronteras que España heredó de repente tras la fulminante caída de ambos imperios.

También la España del siglo XVI pertenecía a una civilización preindustrial cuya tecnología era incapaz de explotar con rentabilidad las tierras estériles del norte de Nueva España. Pero aquella frontera era rica en plata (tan apreciada en Europa), y la soberanía de la Corona sobre cualquier territorio del Nuevo Mundo se justificaba a cambio de la evangelización de sus habitantes. En otras palabras, los españoles estaban movidos por objetivos que sólo se explican en el contexto de su cosmovisión: una economía mercantilista y un sistema de creencias sancionado y presidido por el $\mathrm{papa}^{2}$. Pese a que todas las naciones colonizadoras europeas eran parte de un mismo universo cultural (la civilización occidental), la colonización española tuvo sus propias características. A diferencia de la colonización inglesa, incluso francesa o portuguesa, la exploración y conquista, la posterior ocupación del suelo, y las relaciones de los españoles con el poder metropolitano dieron singularidad al proceso y a sus protagonistas. La "empresa indiana" por decirlo en dos palabras, fue una empresa oficial bajo la autoridad moral de la Iglesia y el poder político de la Corona: las dos majestades, Dios y el Rey. Tras la conquista - a veces antes de lograrse una verdadera pacificación, como en el caso de tantas fronteras - el objetivo era poblar la tierra con españoles y evangelizar al indio. Este doble principio suponía fundar villas y ciudades y crear pueblos de indios. Los españoles recibirían de la Corona indios y tierras en repartimiento, protección contra los enemigos indígenas o extranjeros y otros beneficios y mercedes. El sistema de repartimiento de indios y su enco-

2. En realidad, el norte de México y los actuales estados de Nuevo México y Arizona siguen siendo tierras poco o nada aptas para la agricultura, y de tan baja densidad demográfica que muchas regiones son verdaderos desiertos. 
mienda institucionalizó en el Nuevo Mundo desde el principio, y especialmente en el primer siglo, una relación de dependencia asimétrica entre españoles e indígenas. También los españoles mantuvieron una fuerte relación de dependencia de la Corona sin parangón en otros imperios europeos.

La política española de inclusión del indio, con todos sus abusos y errores, suponía su integración en la nueva sociedad ${ }^{3}$. En vez de eliminar o desplazar a los indígenas con el fin de disponer de espacios vacíos, el imperativo era reducirlos a pueblo. Es decir, congregarlos en establecimientos de nueva planta. Obviamente, los mayores obstáculos se presentaron en las regiones habitadas por nómadas, que rechazaron las nuevas formas de vida hasta el extremo frecuente de producirse la extinción física antes que una verdadera paz. Bajo estas condiciones generales nació y se perpetuó la frontera norte de Nueva España como espacio de confrontación entre indígenas y españoles. La gran distancia sociocultural entre unos y otros fue, paradójicamente, el verdadero obstáculo para la conquista y pacificación de una multitud de bandas y tribus. La superioridad militar no era nada eficiente frente a quienes carecían de una verdadera jefatura a la que decapitar. Los bárbaros asaltaban por sorpresa, huían tras un golpe a sus refugios naturales, hacían la paz para luego romperla, y siempre superaban a los españoles en el conocimiento del terreno. Su destreza con el arco y la flecha también los hacía más eficientes frente a los arcabuces de los españoles. No es pues de extrañar que la guerra en la frontera resultara interminable y creara miedo y odio en la población.

\section{La frontera norte de Nueva España}

Defino como Gran Norte los territorios situados más allá del Valle de México que estuvieron bajo jurisdicción española de manera más o menos efectiva, y durante un tiempo largo se consideraron frontera en el sentido amplio del tér$\mathrm{mino}^{4}$. Esta delimitación incluye los actuales estados septentrionales de México y los estados de Texas, Nuevo México, Arizona y California. La independencia de México puso fin al período español o colonial de la frontera norte. Pero las condiciones de frontera de guerra persistieron en las regiones más septentrionales hasta los años finales del siglo XIX, cuando el Lejano Norte llevaba medio siglo repartido de manera injusta y muy desigual entre México y los Estados Unidos $^{5}$. Características sobresalientes de la frontera norte de Nueva España son

3. Véase Miksell, M., "Comparative Studies in Frontier History". Annals of the Association of American Geographers 49 (1959), pp. 62-74. Según este autor, fueron fronteras de inclusión, o más propiamente de asimilación, la romana, árabe y española. Fueron fronteras de exclusión la "americana" (American), canadiense, australiana y sudafricana.

4. Jiménez Núñez, A., El Gran Norte de México. Una frontera imperial en la Nueva España (1540-1820), p. 80. Editorial Tébar. Madrid, 2006.

5. El tratado de Guadalupe Hidalgo (1848) puso fin a dos años de guerra. La derrota costó a México la pérdida de los territorios al norte del Río Grande. 
su extensión geográfica y su duración de casi tres siglos (1540-1820). No obstante, el rasgo más específico lo representó una población indígena de vida nómada y economía recolectora-cazadora, con algunas excepciones ${ }^{6}$.

El Gran Norte de Nueva España fue una de las muchas fronteras que surgieron como consecuencia de la interacción de españoles e indios. Las fronteras de América no fueron, pues, una línea o un límite sino un espacio de encuentro (generalmente muy violento) entre gentes con culturas diferentes? ${ }^{7}$. Como ya se ha apuntado, todas las fronteras heredadas o creadas por los españoles tuvieron bastante en común debido a una misma política de la Corona y de la Iglesia sobre todos y cada uno de los espacios de encuentro. Al mismo tiempo, la diversidad geográfica, la diversidad de su población nativa, las fechas de comienzo y final de cada proceso, su mayor o menor duración, produjeron una variedad de tipos de frontera ${ }^{8}$. La historia de la frontera norte comenzó con la expedición de Francisco Vázquez de Coronado a Nuevo México (1540-1542). Fue la primera respuesta al deseo y la ilusión de encontrar otro México, otro país rico y densamente poblado, lo que explica la temprana y profunda penetración española en el norte de Nueva España. El fracaso de Coronado quedó compensado poco después con el hallazgo de plata en las tierras de los indios zacatecos (1546)

La condición de bárbaros de los indios de la frontera se manifestó en dos grandes hechos: la guerra y la imposibilidad práctica de asentarlos en pueblos para ser cristianizados (civilizados) y estar en condiciones de servir a la Corona con su trabajo o su tributo. En otras palabras, el norte de Nueva España fue hasta el final del período español - aunque no en todo tiempo lo fue en su totalidad geográfica - frontera de guerra y frontera misionera. De hecho, buena parte de la población indígena se extinguió antes de someterse al poder de la Corona o de aceptar mínimamente la nueva fe. Es cierto que con el paso de los siglos, las regiones más cercanas al centro de México dejaban de ser fronteras en el sentido convencional, pero las tardías incursiones de apaches y comanches mantuvieron el estado de guerra en el norte más lejano.

En la frontera del Gran Norte coexistieron durante siglos el poblamiento y la guerra, el presidio y la misión, la villa o la ciudad de españoles, los nuevos pue-

6. Los conocidos como "indios pueblos" de Nuevo México son la gran excepción, como es excepcional la cuenca del Río Grande que había permitido desde hacía siglos una agricultura imposible o muy poco efectiva en las tierras eminentemente áridas del Gran Norte.

7. Véase Weber, D. y Rausch, J., eds. Where cultures meet. Frontiers in Latin American History. Scholarly Resources Inc. Wilmington, Del., 1994. La primera parte del título de esta recopilación es una útil definición de frontera.

8. Véase, por ejemplo, Jiménez Núñez, Alfredo, "El fenómeno de frontera y sus variables. Notas para una tipología". Estudios fronterizos 40 (1997), pp. 11-25.

9. Los años anteriores pertenecieron al típico proceso de conquista rápida como la victoria sobre los aztecas por Hernán Cortés o la actuación violenta y despiadada de Nuño de Guzmán, que le permitió, aunque de forma muy incompleta y precaria, la fundación de Nueva Galicia como primer reino o provincia de la frontera norte. 
blos de indios y las sublevaciones periódicas, el real de minas, la ganadería extensiva, la precaria agricultura, la gran propiedad, el mísero rancho. En la frontera norte convivieron, malvivieron o murieron trágicamente el español y el bárbaro, el poblador y el indígena. En este escenario tan distinto a otras regiones de la América española o inglesa, hay que contemplar y tratar de entender a quienes no eran colonos, settlers, pioneers o frontiersmen ${ }^{10}$. Tampoco aqueIlos españoles eran ciudadanos sino vasallos del rey. La ciudadanía es un concepto y un fenómeno social nacidos de la Revolución Francesa. La mejor designación para los que no era militares ni eclesiásticos es la de vecinos o cabezas de familia que constituidos en cabildos o ayuntamientos defendían sus intereses y se relacionaban como grupo con las autoridades.

Tanto la población urbana como rural era diversa al estar formada en distintas proporciones por españoles, mestizos, indios, negros, mulatos " $y$ otras castas", como dice la coletilla de tantos documentos de la época. Había, además, notables diferencias dentro de la población de españoles, algo natural en toda sociedad compleja. En lo más alto estaban los hombres ricos y poderosos, dueños de grandes haciendas y de minas que, en buena parte, hicieron su fortuna en los primeros tiempos combinando la conquista y la ocupación de altos cargos con la actividad empresarial. De la fortuna de uno de aquellos hombres surgió a finales del siglo XVII el marquesado de Aguayo, con fabulosas propiedades de tierra. Pero los grandes ricos, además de ser pocos, solían vivir en la ciudad de México, y aunque sufrían en su economía los zarpazos de la guerra y de la naturaleza, no padecían tales daños en sus personas. El sector que venimos calificando como vecinos estaba formado por mineros de desigual e inestable fortuna y dueños de haciendas o ranchos, generalmente con casa en la villa o ciudad y en el campo; por mercaderes y comerciantes, y algunos profesionales como letrados, escribanos o médicos; por artesanos de diversos oficios. Completaba la lista una masa de hombres y mujeres de servicio, peones y otros trabajadores sin cualificación. Sobre los hombres de mayores medios y mejor reputación recaían cargos electos de alcaldes y regidores así como los nombramientos para diversos empleos en la vida pública. Eran estos habitantes de villas o ciudades, de reales de minas, haciendas y ranchos los que vivían sujetos a los asaltos y levantamientos de los bárbaros. El peligro era todavía mayor y más constante a lo largo de los caminos, y los arrieros y sus familias las primeras víctimas.

10. El término colonia fue muy tardío y siempre raro en la América española. En el Norte, se estrenó con la fundación de la Colonia del Nuevo Santander a mitad del siglo XVIII. Casi ninguno de los términos referidos a los angloamericanos en su expansión hacia el Oeste tienen justa traducción al español porque definían en su tiempo situaciones históricas y estatus sociales inexistentes en el poblamiento (que no colonización) de la frontera norte. Cuando el Oeste americano imita al Norte español (por razones ecológicas, entre otras) no traduce sino que adopta palabras para nombrar lo que ya existía. Ejemplos, buckaroo (vaquero), corral, lariat (la reata), lasso (lazo), rancho, rodeo, sombrero, stampede (estampida). 
Los indígenas de la inmensa frontera norte pertenecían a una multitud de tribus y hablaban un número aún mayor de lenguas y dialectos. No hubo una lingua franca, como lo fue el náhuatl en el centro de México. Esta diversidad lingüística fue un grave obstáculo para la evangelización de unas tribus nómadas o seminómadas. Tampoco favoreció la relación con los españoles pues unos vivían aislados en sus pueblos de misión y otros eran trabajadores más o menos forzados en minas o haciendas, cuando no esclavos. Una gran novedad en la composición étnica de la frontera fue la traída de tlaxclatecas y otros indios civilizados del centro de México para que con su ejemplo estimularan a los bárbaros a la vida sedentaria y a la práctica de la agricultura y otras labores. Fue así, por medidas políticoadministrativas de unos intrusos europeos, cómo el indio mesoamericano traspasó la milenaria barrera ecológica.

\section{Testimonios}

Es evidente que la guerra fue la constante que dominó sobre todas las demás las relaciones entre los vecinos españoles y los indios bárbaros. Los españoles hablaban de "hostilidades" que, por supuesto, fueron mutuas en un juego incesante de acción / reacción. La guerra entre los indígenas era parte de su cultura, y la siguieron practicando entre sí durante el período colonial, aunque los españoles se convirtieron en el enemigo común, especialmente en sus frecuentes rebeliones. Grandes novedades en materia de guerra fueron el caballo y las armas de fuego, elementos de los que supieron hacer buen uso los indígenas. Al mismo tiempo, el robo de caballos y de ganado mayor se convirtió en la mejor presa para unas tribus que vivían de la caza. Con frecuencia, los daños de la guerra en la frontera iban acompañados y se hacían más graves al coincidir con males naturales como sequías o plagas. Conocemos los efectos de la guerra sobre los vecinos españoles a través de los continuos informes de gobernadores y capitanes de presidio. Asimismo, los obispos daban cuenta en sus cartas al rey del estado en que vivía la población. Más directa y personal era la información de los propios vecinos, que en sus cartas y testimonios anexos ofrecían datos y expresaban sentimientos de condena, temor y súplica. El testimonio más significativo eran las cartas dirigidas al virrey o al monarca por un cabildo o ayuntamiento"

En el conjunto de esta información se observan diversidad de opiniones sobre el estado de la frontera y los posibles remedios así como críticas o elogios sobre la actuación de otras autoridades o de los propios vecinos. Es notable la ambivalencia respecto de los indios sobre los cuales abunda, lógicamente, la condena aunque no faltan el reconocimiento a su valor y habilidad para la guerra ni la acusación contra los propios españoles por sus abusos. La diversidad

11. Especial relevancia tenían los largos y precisos informes de los grandes viajes de inspección realizados durante el siglo XVIII. Véase, por ejemplo, Jiménez Núñez, A., El Gran Norte de México, 141-189. 
en los testimonios se debía a unos cuantos factores. En primer lugar, el estado de la frontera y la propia frontera como espacio geográfico variaron a lo largo del tiempo. Por otra parte, el estatus de quien escribía marcaba necesariamente el contenido y el sesgo del documento. Eran necesariamente distintas de otras la visión y conducta de los militares hacia el indio porque su misión era pacificar, incluso por la fuerza; defender con las armas la tierra y sus habitantes, incluidos los indios de paz; reprimir y castigar las sublevaciones.

Por su parte, los vecinos pretendían sobrevivir y medrar en una frontera inevitablemente de guerra. Al mismo tiempo, buscaban en el indio mano de obra para sus minas y haciendas de ganado o labor. Ante pocas o ninguna encomienda de indios tributarios — como las hubo en el centro de México- la utilidad del indio se reducía al trabajo asalariado; incluso, al trabajo forzoso en contra de la política de la Corona. En cualquier caso, los testimonios que aparecen a continuación tienen la virtud de haber sido en su día parte de la comunicación rutinaria. No eran historia o narración hecha por encargo o para ser conocida por la posteridad.

Los vecinos de Compostela, una ciudad por entonces en los mismos márgenes de la frontera, carecen de lo más necesario según escriben a S. M. en carta de 1533:

“En lo demás, V. M. sepa que no tenemos una herradura para herrar ni armas ofensivas ni defensivas, ni las quieren traer, y si alguno viene pide más oro que pesa; ni hay herramientas para buscar oro, porque no hay con qué se paguen, ni un zapato que nos calzar y, finalmente, ninguna cosa de las que para pasar la vida son necesarias, porque a cabo de estos años y más que ha que aquí andamos en servicio de Dios y de V. M. no ha quedado cuero ni correas sino la voluntad muy leal que de servir a V. M. tenemos"12.

El cabildo de Guadalajara, capital de Nueva Galicia, demanda al rey en 1572 "remedio" y "socorro" y alude a los procuradores que van camino de España para presentar personalmente las demandas ante el Consejo de Indias:

"El cabildo, justicia y regimiento de esta ciudad de Guadalajara humildemente y como leales vasallos y servidores de V. M., besamos sus reales manos y decimos que por otras nuestras cartas que tenemos escritas a $\mathrm{V}$. M. y a su Real Consejo muy particularmente, hemos informado de lo que toca y conviene al servicio de Dios Nuestro Señor y de V. M. como a aquéllos que están en este Nuevo Mundo y destierro tan remoto y apartado de nues-

12. Cabildo de Compostela al rey, 29 febrero 1533. Archivo General de Indias, Audiencia de Guadalajara 30. En adelante, AGI. 
tro propio natural, esperando siempre el socorro y favor de V. M., pues no tenemos otro después de Dios, y estamos muy desconsolados en ver que a cabo de tanto tiempo no tengamos alguna lumbre de nuestros negocios; y de lo que V. M. tenemos escrito, que no sabemos si es por falta de nuestros procuradores o que V. M. o su Real Consejo nos tenga olvidados, porque es cierto que sentimos más esto que todos nuestros trabajos pasados y presentes, que son hartos, porque desde que entramos en esta conquista y nuevo reino se pobló hasta ahora, no damos paso que no sea con las armas a cuestas como a V. M. le es notorio por las muchas probanzas que cada día de este nuevo reino van a ese Real Consejo haciendo relación de lo que pasa y pidiendo el remedio para tanto mal y trabajo y desasosiego como estas bárbaras gentes dan cada hora, y nuestra necesidad de por sí que ya V. M. sabe. Lo que este nuevo reino y la necesidad y miseria que en él se pasa, que el mayor repartimiento no tiene ni pasa todos los más de ellos de doscientos pesos, y para sustentar lo que conviene y para tener caballos y armas y lo demás necesario es muy pequeña ración para tanto trabajo y en tierra tan extraña; con todo esto, como ya estamos a cabo de tanto tiempo hechos al trabajo y miseria y desasosiego de esta tan ordinaria guerra, pasaríamos pues que Dios ha sido servido de darnos esta plaga...".

El resto de la carta es una denuncia contra el mal gobierno de la audiencia y una demanda de remedios. La despedida es típica de aquellos vasallos siempre tan quejosos como fieles:

"Nuestro Señor guarde y prospere la Católica, Cristiana, Real Majestad largos tiempos con mayores estados y reinos y acrecentamiento de ellos y vencimiento contra los infieles como estos leales vasallos de V. M. lo desean"13.

Unos españoles hacen al virrey la siguiente descripción del estado de la frontera en 1582, en plena Guerra Chichimeca, ${ }^{14}$ cuando las hostilidades se producían justamente en los límites con el área de México Central:

"Al muy excelente señor: Los criadores de ganados vecinos y moradores de la frontera de los chichimecas decimos que a vuestra excelencia consta y es notorio los excesos, muertes y daños y robos que los indios chichimecas salteadores rebelados del real servicio de S. M. han dado en hacer en la dicha frontera y en los caminos, pueblos y estancias de su comarca... (...) ... la insolencia y atrevimiento de los indios ha crecido tanto que no solamente han continuado los daños, pero se han hecho tan fuertes y mañosos que han dejado sus tierras y las sierras y quebradas que tenían por

13. Cabildo de Guadalajara al rey, 23 diciembre 1572. AGI, Audiencia de Guadalajara 30.

14. La Guerra Chichimeca fue un estado general de violencia en la Nueva Vizcaya que ocupó toda la segunda mitad del siglo XVI. Los virreyes intentaron políticas diversas que variaron desde las proposiciones de paz hasta "la guerra a fuego y sangre". 
su defensa y se han bajado a lo llano, y de pocos días a esta parte han dado muchos asaltos en los pueblos de paz y muerto mucha gente, así en ellos como en los caminos y estancias, ejecutando en ellas sus acostumbradas crueldades desollándoles las cabezas y sacándoles vivos los corazones y entrañas y quemado y profanado iglesias, y aún les está probado comer carne humana de las personas que matan, y totalmente han arruinado y destruido los pueblos y estancias, y para hacerse más fuertes han robado y llevado tantas yeguas y caballos que los dueños han quedado tan destruidos y perdidos que han despoblado sus estancias sin poder volverlas a criar; y por no haber hallado resistencia, los dichos salteadores han venido a hacer daños veinte leguas de esta ciudad, y según sus victorias y buenos sucesos, si con tiempo no se acudiese al remedio podría ser que cuando se quisiese remediar no fuese posible sino con gran costa y menoscabo de la real hacienda de S. M. y pérdida de sus vasallos, porque con el ánimo y osadía que tienen podrían con facilidad arruinar y destruir las provincias que confinan con ellos por ser de indios otomíes y tarascos, que es gente flaca y miserable y sin defensa ni armas correspondientes a las suyas..." ${ }^{15}$.

El siglo XVII se distinguió en el Gran Norte por el número y gravedad de las sublevaciones. Además de la guerra contra los "gentiles" o indios no sometidos ni bautizados, los españoles se enfrentaron a la reacción de indios bautizados y asentados en pueblos años atrás que, de repente, se alzaban utilizando conceptos e instrumentos tomados de los propios españoles. Era la consecuencia de una integración muy deficiente y hasta de una aculturación antagónica ${ }^{16}$, pues los cabecillas se hacían pasar por obispos, prometían la inmortalidad, hablaban lenguas... Eran intentos tardíos de acabar con los abusos o de liberarse de la sujeción política con la promesa de volver a los tiempos antiguos. Estas reacciones causaron muchos muertos entre los dos bandos. Por la lógica de estos movimientos mesiánicos, nativistas o revivalistas, las primeras víctimas españolas eran los padres misioneros ${ }^{17}$.

La situación a mitad del siglo XVII en la región de Parras, en el corazón de Nueva Vizcaya, era desesperada. Así la describe doña Isabel de Urdiñola, hija del que a principios de siglo había sido gobernador de la provincia, y madre de la esposa del actual gobernador:

"En arroyos de lágrimas escribo a V. S. estos breves renglones no más de hacer sabedor a V. S. que estamos por horas aguardando el perder las

15. Petición ante el virrey de los criadores de ganados. AGI, Patronato 181.

16. Se trata de aceptar algo para rechazar mejor el todo. Véase Devereux, G. y Loeb, E., "Antagonistic acculturation", American Sociological Review 8 (1943), pp. 133-148. Hay alguna referencia a los apaches.

17. La primera gran sublevación fue la de los tepehuanes (1616-1618). Los tarahumaras se levantaron por tres veces entre 1648 y 1652. La rebelión en 1680 de los indios pueblos de Nuevo México obligó a los españoles a abandonar la provincia e instalarse en El Paso, punto límite entre Nuevo México y Nueva Vizcaya. Allí permanecieron hasta la reconquista en 1692. 
vidas, porque no entendimos que estábamos con el riesgo que hoy estamos, y a los enemigos muy a la puerta, cada hora con mil sobresaltos temiendo algún mal suceso así de las vidas y malogro de la prenda de $\mathrm{V}$. S. porque, aunque su esposa de V. S. tiene mucho ánimo, son muchos los sobresaltos, y no puede haber resistencia del temor que es natural, y más el de la muerte. Ayer tuvimos nuevas de cómo mataron a Molina y a su hijo y todos los que vinieron por bastimentos de Mapimí en Santa Ana, y se llevaron vivas tres mujeres que traían, de manera que sólo un indizuelo se escapó milagrosamente; y anoche llegó uno de los matadores con arcabuz y los vestidos de los muertos en casa de un indio de este pueblo. Yo tengo hecha toda la prevención posible; no me parece que basta porque dicen son muchísimos los indios que están de Santa Ana para acá y así, por amor de nuestro Señor, que si nos quiere ver vivas V. S. que luego al punto vengan a seguir a estos enemigos, que si en esto hay la mayor dilación, sin duda pereceremos todos".

"En esta casa se han recogido los padres y estamos todas las noches sin pegar los ojos con mil temores de cuándo será la hora que lleguen; y por estar estos caminos ya con tanto riesgo, envío este despacho por Bonanza a salir a Cuencamé para que tenga V. S. este aviso y se duela de nosotros y de esta prenda, que tengo mi alma atravesada de mil congojas y aflicciones, y así no me puedo alargar más, que aunque estos días he andado achacosa, y todo se junta con tantas penas, sea el Señor loado. No escribe su esposa de V. S. porque no le digo de este despacho, porque no se enternezca y le vengan mayores penas".

"No tenemos pólvora, y aunque despachamos luego el correo que trujo las cartas de V. S. con mula de carga, fue para que enviase V. S. la pólvora. Temo que le habrán muerto en el camino de Cuencamé, y lo propio sucederá a los carros, y así deténgalos V. S. o se vengan por Bonanza que, como digo, toda la gente de indios están en estos contornos y así se hará buena presa con buenas compañías de soldados. Por amor de Dios, sea con toda la brevedad posible y el socorro, y si el padre Castillo no Ilega, ay, lo habrán muerto sin remedio. No tengo más que encargar a V. S. mas de nuestras vidas, que las deseamos para servir a V. S. y gozar de su presencia, que estoy tal que aún no entendí poder escribir estos renglones. Y guárdeme nuestro Señor a V. S. los años tan felices como yo deseo. (...) Parras y mayo 17 de 1645 años. (...) Beso la mano a V. S. quien más que así lo ama y quiere, Doña Isabel de Urdiñola"18.

El cabildo de Durango, capital de la Nueva Vizcaya y sede del obispado, describe al virrey el estado en que vive la población en 1681. Tanto la población urbana como el campo sufren los ataques de los indios Al final del testimonio se habla de "aflicciones"; con suerte, de la posibilidad de salir huyendo:

18. Isabel de Urdiñola al gobernador, 17 mayo 1645. AGI, Audiencia de Guadalajara 38. 
“... y a tanto, señor, ha llegado la demasiada osadía de estos indios y poca resistencia que los refrene con el corto número de soldados, que ha pocos días se vio esta ciudad y sus contornos acometida por todas partes, y ya que las muertes hechas habrán llegado al número de veinte personas, sin otras que llevaron vivas, no reservando su crueldad mujeres ni criaturas de pecho en que no (sic) se ve su saña. Importa muchos dineros la cantidad crecida que se han llevado de caballada faltando con esto las yeguas para la cría de mulas, principalísimo menester para el avío de las haciendas de minas, que es el fruto más principal que dan los muchos minerales de este reino, descaecidos [desalentados] todos por el temor de ser asaltados por instantes".

"Viéndonos en este aprieto y recelando Ilegasen hasta nuestras casas, dimos cuenta a D. Bartolomé de Estrada, nuestro gobernador y capitán general de este reino, quien atendiendo a sus muchas obligaciones, y a la especial a ser de su cuidado el mantenerlo y conservarlo en todo lo que sea posible, vino en persona con los quince infantes de los treinta soldados de campaña que por entonces se hallaron prontos a causa de estar los pocos que quedan en otras fronteras tan necesitadas como ésta, y distantes mucho unas de otras, y aunque nos deja ocho de los quince que consigo trajo $\mathrm{S}$. S., cincuenta, señor, serían bastantes a sólo contener, no a sujetar los indios, así por ser muchos como por la diversión que hacen sus invasiones a todas partes sin que pueda saberse nunca con seguridad su designio, tanto que sólo es aviso del daño el haberlo hecho. En cuya consideración suplicamos a V. S. mire este reino con los ojos a que su necesidad le moverá, y así mismo entendido de que sin el estorbo de estos indios, es la más rica alhaja que tiene S. M. en estas Indias, y que lo fertilísimo de sus cosechas en todo género de semillas y frutas no llega a lo riquísimo de sus minerales, todo lo cual cesa y a más andar se acaba por los temores dichos; pues ni es posible cultivar las tierras ni labrar las minas, con que necesariamente se puede esperar no sólo en pocos años sino en algunos meses, su total ruina, pues aunque hubiere sustento bastante, faltando las minas y su plata, que es la que trae la guerra, el dinero y lo demás necesario para la conservación de esta vida. Los pocos que hoy vivimos en estas aflicciones acabaremos sin recurso o a buen librar (si nos lo permiten) nos saldremos huyendo"19.

A la reiterada pérdida de vidas humanas a manos de los bárbaros seguía con frecuencia el abandono de los campos, otra manera de morir que también afectaba gravemente la economía. El gobernador de Nueva Vizcaya Juan Isidro de Pardiñas escribía en 1688:

"Lo más de este reino es despoblado de españoles porque como ha sido continua la guerra en él, no se atreven a poblar muchas partes que hay cómodas para poblaciones por la poca seguridad que tienen por las inva-

19. La ciudad de Durango al virrey, 17 abril 1681. AGl, Audiencia de Guadalajara 29. 
siones de los enemigos, no obstante que en el tiempo que ha que me hallo con este cargo no he dejado las armas de la mano haciéndoles guerra, cuya obstinación ha sido y es tanta que ni aun por el medio suave de la paz los he podido reducir, porque como es todo este reino tierra tan abierta y en muy larga distancia, por cualquier parte entran a invadir, robar y matar causando tanto perjuicio que, cuando menos consiguen, se llevan las caballadas y muladas que pastan los campos, frustrando el beneficio de sacar plata (porque sin ellas no se puede hacer) ${ }^{\prime 20}$.

En 1750, la voz de los vecinos se oye clara y fuerte en informes como el enviado en el mes de abril al gobernador de Nueva Vizcaya desde el Valle de San Buenaventura, al noroeste de Chihuahua:

"Los vecinos del Valle de San Buenaventura y dueños de hacienda en él y su jurisdicción (...) que abajo firmamos (...) urgidos de la suma necesidad con que no tan solamente a la presente nos hallamos sino también por las que antes de ahora hemos pasado, como a V. S. le pueden ser constantes por los repetidos informes que a sus antecesores tenemos hecho de las continuas invasiones y asaltos que hemos recibido y recibimos cuasi diariamente de los enemigos indios bárbaros, cuyos daños son continuas lágrimas y gemidos que padecen muchas viudas y huérfanas por la pérdida de las vidas de sus maridos, padres y hermanos que a manos de dichos bárbaros han rendido el último aliento en defensa de sus familias, patria y del aumento del real erario de S. M., y sin que hasta ahora hayamos tenido el más leve alivio o socorro que la providencia humana pueda tener. En esta atención y sin que la de V. S. se dé por molestada, todos y cada uno de por sí rendidos a sus pies pedimos con toda vera nos proteja y ampare en semejantes necesidades providenciando auxiliarnos con las armas de $S$. M. (que Dios guarde) por hallarse las nuestras totalmente descaecidas [desalentadas] por falta de hombres y caballos y, por lo mismo, los pocos que hemos quedado a veces no nos hallamos suficientes para la defensa de nuestras familias que, aunque tenemos a distancia de treinta y cinco leguas el real presidio de Janos comandado por el capitán don José Díaz del Carpio, no puede éste y sus infantes darnos el pronto socorro que a cada paso necesitamos así por las muchas leguas que dista de este Valle como también por tener algunos días a una escuadra de soldados en las marismas de la nación de los seris, provincia de la Sonora, castigando el orgullo de aquella nación indómita, y los demás le son muy precisos para la guardia y custodia del dicho presidio y su situado. En esta atención de nuevo y rendidamente suplicamos a la piedad de V. S. se sirva auxiliarnos remitiéndonos los soldados que en la actualidad se hallaren en esa villa o sus inmediaciones para que agregados a ellos algunos de los pocos veci-

20. Pardiñas al rey, 21 noviembre 1688. AGI, Audiencia de Guadalajara 29. 
nos que a la presente hemos quedado puedan registrar la tierra, cortar rastros, los que a cada paso se encontrarán, y por ello se puede seguir al enemigo y dar en las rancherías que tienen en la inmediación de este valle no a larga distancia, que la que más Ilegará a diez o doce leguas, viniendo en ellas dichos indios enemigos con tal confianza y seguridad que no respetan ni temen asaltar las conductas de las recuas sus escoltas ni otra cualquier prevención, Ilegando a tan subido grado su audacia que sin respeto alguno se arrojan a las casas de este valle y las de su distrito, robando las pocas caballadas, muladas, ganado mayor y menor que han quedado, cautivando personas grandes y pequeñas y matando a otros como lo verifica la expresión que aquí haremos y de lo que ha pasado desde el último informe que a V. S. tenemos presentados desde el año pasado, para lo cual necesitamos su grata atención..."21.

En aquellos años centrales del siglo XVIII, la situación en la Nueva Vizcaya era ciertamente angustiosa por la combinación de los males causados por la naturaleza y por las hostilidades de los indios. Una vez más, la autoridad eclesiástica se hace eco de las desgracias que vive la población.

“El obispo y cabildo de la Santa Iglesia Catedral de Durango, reino de la Nueva Vizcaya, hace relación de los infortunios que la esterilidad insólita de tres años continuos ha causado, de los levantamientos de indios, desolaciones de haciendas, miserable estado en que se halla la Iglesia... (...) Desde el año de 738 ha sido la escasez de aguas en todo este obispado tan grande que de ella se ha seguido la total ruina de las mejores haciendas, muriéndose como se han muerto los más de los ganados, así mayores como menores, sin que con especialidad en los dos años más calamitosos, que han sido los de 49 y 50, haya habido hacienda que pueda haber quedado en pie, ni de lo muy poco que pudo diezmar satisfacer el diezmo, despoblándose como se despoblaron los lugares por el hambre, de que murió muchísima gente; y la que de las haciendas y lugares circunvecinos se salió muchas de ellas se nos vino a esta ciudad, inundándose el palacio episcopal, casas de los prebendados, pidiendo de justicia el socorro y alimento que en tales ocasiones, con mayor vínculo que en otras, estamos obligados a darles. (...) Yo el prelado, como cabeza, y nosotros los prebendados como miembros del cuerpo de esta Iglesia, todos nos dedicamos a socorrer en cuanto nuestras fuerzas alcanzaron a los innumerables pobres de que todavía está llena esta ciudad, sin haber reservado cosa que no se les hubiese franqueado en medio de haber habido temporadas en que no hemos tenido un pan que poder llegar a la boca, ni un pedazo de carne, aun para algunos enfermos, Ilegando a tal nuestra desdicha que no pocos meses el alimento de un obispo era una poca de leche,

21. AGI, Audiencia de Guadalajara 110. 
más para estragar el estómago que para mantener la vida; que si esto, en quienes pudieran haberse valido de los diezmos, como administradores de ellos, ha sucedido, de aquí podrá el alto y soberano entendimiento de V. M. comprender el extremo a que llegarían las necesidades de los ranchos y lugares cortos y las de los que no pudieron venir al refugio de esta ciudad. Lo que en ella vimos fue que como podían se salían a los campos y partes donde pudieran hallarse algunas raíces para cavarlas y sustentarse de ellas como de las del maguey, que llaman mezcal, de nopales silvestres secos y áridos, de palma silvestre, y otras, y de las pieles que quitaban a las reses o bestias que hallaban muertas en el campo, tostándolas y tomándolas sin otro condimento, de que fue tan perniciosa la resulta de fiebres, garrotillos y otros accidentes, que sólo por milagro de la Santísima Reina y Señora de Guadalupe nos parece no haberse acabado todo este reino entero y V. M. perdido lo no menos precioso de su Real Corona"22.

En la segunda mitad de la centuria ocurrieron grandes hechos en el Gran Norte. En el marco del largo reinado de Carlos III (1759-1788) se creó la Comandancia General de las Provincias Internas (1776). Poco antes había conocido buena parte de la frontera don José de Gálvez como visitador general de Nueva España (1765-1771); vuelto a España, Gálvez fue nombrado presidente del Consejo de Indias y ministro de Indias (1776-1787). También en aquellas décadas se produjo la expulsión de la Compañía de Jesús, que afectó seriamente a las importantes misiones jesuitas de la frontera. De todas estas medidas fue Gálvez el gran impulsor. El espíritu de la Ilustración también se dejó sentir en nuevos métodos y actitudes hacia el indio de guerra por parte de las autoridades, de cuyos testimonios se ofrece a continuación una muestra.

El virrey Bucareli envió a Madrid en enero de 1773 un informe detallado y al mismo tiempo conciso sobre el estado de la frontera. Entresacamos de dicho documento noticias y comentarios muy significativos que se comentarán más adelante. La transcripción que sigue es prácticamente literal, aunque no vaya entre comillas, y se mantiene el tiempo verbal que el virrey usa en la narración de los hechos.

En Nueva Vizcaya, en una operación de desalojo de indios apaches del Bolsón de Mapimí, han participado tres indios concheños, hombres ancianos, amigos y prácticos del país. Otros diez indios auxiliares de las misiones de Coahuila acompañan a los soldados que se han sumado a la operación. En Sonora, los indios gentiles que habitan la Isla del Tiburón han ofrecido la obediencia al Rey, pidiendo se les pongan ministros que les instruyan en los dogmas de nuestra santa fe. Los indios de la Papaguería acreditan cada día más su amistad y la buena fe con que proceden. El gobernador de Comaquibuto se presentó el cinco de octubre último en nombre de todos los gobernadores de la nación papaga al

22. El obispo, deán y cabildo de Durango al rey, ca. 1750. AGl, Audiencia de Guadalajara 208. 
capitán de Santa Gertrudis del Mar entregándole una tarja cuyas señales o rayitas significaban haber muerto diez hombres y veintiuna mujeres apaches, que son sus irreconciliables enemigos, y cautivándoles seis niñas. El capitán agasajó al gobernador con un pequeño regalo, y habiéndolo recibido se retiró a su país prometiendo en nombre de su nación continuar la guerra a los apaches.

Más extensas son las referencias del virrey a Nuevo México, la provincia de los indios pueblos que habitaban las márgenes del Río Grande. El día veintidós de julio del año próximo anterior de 1772 atacaron al pueblo de Pecos más de quinientos comanches, pero fueron rechazados con la pérdida de nueve de ellos y sin daño de los nuestros. Lo mismo han ejecutado por cinco veces hasta en número de doscientos con el pueblo de Pecuríes, sin haber logrado otra ventaja que la de dar muerte a dos indios que hallaron en sus milpas distantes de dicho pueblo, y herido gravemente de un balazo a un vecino, bien que a costa de diecisiete comanches que quedaron muertos en la campaña. Iguales insultos han hecho estos bárbaros en el pueblo de Galisteo por cuatro ocasiones. En una de ellas sorprendieron treinta indios que hacían la pisca [recogida] de sus maíces, y aunque eran cientos los comanches, se defendieron vigorosamente los galisteos, logrando retirarse a su pueblo, en cuya refriega murieron tres de éstos, quedando siete heridos. De los enemigos perecieron seis y también hubo muchos heridos. El gobernador despachó inmediatamente una partida de tropa y vecinos en seguimiento de los comanches, y habiéndolos alcanzado dieron muerte a doce, apresaron una mujer y obligaron a los demás a que se pusiesen en fuga, dejando todo su equipaje y como hasta sesenta cabalgaduras, que se repartieron entre los vecinos. De este combate salieron heridos cuatro indios y un indio auxiliar. Sin embargo de los referidos procedimientos, no hallan inconveniente los comanches en presentarse de paz en el pueblo de Taos a comerciar sus efectos, que consisten en pieles de cíbolo, caballos, mulas, algunos fusiles y piezas de cautivos, cambalachando por frenos, leznas, cuchillos, ropas coloradas y maíz, de que resulta beneficio a los vecindarios de la provincia. En una de estas ferias dispuso el gobernador se entregase a uno de los principales capitanes un hijo suyo que se hallaba prisionero, de cuya acción agradecido el comanche ofreció la paz en nombre de toda su nación, restituyendo dos cautivos españoles. Los apaches hostilizan también esta provincia, aunque con más cautela. Han hecho varios robos, y dado muerte a algunos indios amigos, pero la vigilancia de éstos y de los vecindarios les hacen desgraciadas sus ideas, como se verificó en el pueblo de Zuñi. A éste se arrojaron en número de cincuenta, mataron tres hombres y tres mujeres, pero los zuñis dieron muerte a veintidós apaches y los demás huyeron malheridos. Esta nación ha ofrecido igualmente la paz, pero como no saben guardar la fe que prometen, fácilmente quebrantan sus palabras, disculpándose con que los daños los ejecutan otros de diferentes rancherías ${ }^{23}$.

23. Bucareli a Arriaga, presidente del Consejo de Indias, 27 enero 1773. AGI, Audiencia de Guadalajara 513. 
En otro informe del virrey Bucareli a José de Gálvez se lee lo siguiente:

“También avisa [el brigadier Hugo O'Conor] que los apaches conocen la fuerza de las armas del Rey, su propio riesgo, y que por no verse perseguidos en todas partes aspiran a la paz; pero las experiencias que hay de su infidelidad y del amor que tienen a la vida ferina, a la libertad y al robo, ponen el efecto en desconfianza. El comandante inspector habla de este particular con alguna esperanza, no dudando procedan tales noticias del escarmiento en que es preciso se hallen aquellas combatidas naciones, pero yo que veo continuamente los daños, aunque se atribuyan a rateros, necesito mayores pruebas para persuadirme a que se cumplan los indicados preludios de la reducción" ${ }^{\prime 24}$.

El citado O'Conor redactó en 1777 un extenso informe sobre el estado de la frontera norte, que en buena parte había recorrido en viaje de inspección ${ }^{25}$. El informe iba dirigido a Teodoro de Croix, recién nombrado comandante general de las Provincias Internas. El gran problema lo presentaban los apaches, aunque $\mathrm{O}^{\prime}$ Conor se pronuncia también sobre otros grupos indígenas y sobre las tropas españolas ${ }^{26}$. Contrastan las actuaciones de los apaches con el comportamiento de otros muchos grupos que vivían en paz y dedicados a sus labores en el campo. El brigadier no omite sus acusaciones por los excesos cometidos por los propios españoles. Comienza el informe con el recuerdo de los destrozos, robos, muertes y otros daños causados por los apaches en numerosos pueblos de indios y de españoles en la provincia de Nueva Vizcaya. Y continúa:

"Por oriente y sur de Chihuahua se hallaban igualmente desamparadas varias haciendas y poblaciones. Las del Saúz, a dieciséis leguas de aquella villa, en que estuve alojado, el día antes de llegar a ella acababa de padecer uno de los muchos insultos que los indios acostumbran. No habiendo hallado en ella gente, rompieron las puertas, la entraron a su arbitrio, destrozaron escritorios, mesas, sillas, cajón de ornamentos, capilla, y cuantos muebles hallaron en ella, por complemento de su ferocidad y desahogo de su venganza. (...) Pero era objeto de mayor compasión las muchas personas que han perdido repentinamente las vidas a la crueldad de los bárbaros, sin perdonar sexo ni edad, pues despedazaban las criaturas en los pechos de sus madres, y aun en sus vientres, ejecutando en los difuntos cuerpos los más detestables excesos de la ferocidad y sevicia" (14 a 17).

24. Bucareli a Gálvez, 27diciembre 1776. AGI, Audiencia de México 1378.

25. O'Conor fue comandante inspector de los presidios y gobernador de Tejas (1767-1770). Este soldado pelirrojo y de origen irlandés era conocido por los indios como el Capitán Colorado.

26. Cutter, D., ed. y trad., The Defenses of Northern New Spain. Hugo O'Conor's Report to Teodoro de Croix, July 22, 1777. Southern Methodist University Press. Dallas, 1994. El informe está organizado en ocho apartados y en breves párrafos numerados del uno al 246 que nos sirven de referencia en las citas. 
"En la guerra que se haga contra los apaches, siempre opinaré como conveniente que se emplee a los fidelísimos ópatas, así por su acreditado valor como por su gran conocimiento de los terrenos, sierras y aguajes en que habitan los indios apaches del poniente. (...) Jamás hubo ejemplar de que faltasen al cumplimiento de cuantas órdenes se les comunicaban, manifestando en todas ocasiones el constante amor que profesan a los españoles, cuyo hechos con su aplicación a la agricultura, afán con que procuran enseñar la doctrina cristiana a sus hijos, y su particular esmero en el culto divino les hace en mi concepto acreedores a que sean atendidos y mirados con amor, distinguiéndoles de las demás naciones" (221).

De los seris y pimas altos, escribe $\mathrm{O}^{\prime}$ Conor que "a todos los vi cuando estuve en la provincia [de Sonora] con muestras a mi parecer de mantenerse quietos y fieles y aplicados los más de ellos a la agricultura, excepto unas veinte familias que desertaron el terreno y a quienes se han atribuido algunos daños acaecidos..." (226). Igualmente elogia la laboriosidad, fidelidad y quietud de los pimas y yaquis (227). Volviendo sobre la provincia de Nueva Vizcaya dice $\mathrm{O}^{\prime}$ Conor que allí,

"viven en diversos pueblos las vastas crecidas naciones de la Tarahumara Alta y Baja, y éstos, a título de apaches, son los que cometen muchos daños en lo interior de ella. Pero estos excesos, si no me engaño, provienen del ningún arreglo en las poblaciones y en la vejación con que les tratan pues estando prevenido por ley que los mandamientos que se libren sean para la tercia parte de los indios de cada una, se cometen excesos grandes, de modo que hay vez que ninguno queda en el pueblo para atender a la familia de los ausentes" (228). "Síguese a este tirano perjuicio la mala paga de los hacendados y el peor modo con que se les trata, y como por su ausencia en los tiempos precisos de siembras y cosechas les llega a faltar el mantenimiento, ven a sus familias en cueros y muertas de hambre. No es extraño que resueltos a buscar auxilios cometan robos y otros daños para sufragar la necesidad, cayendo en el error de muchos homicidios para no ser descubiertos" (229).

De los indios de Nuevo México escribe O'Conor:

“... sé que todos se dedican pacíficamente a la agricultura de sus tierras y a la cría de ganados mayores y menores, de que disfrutan en tal abundancia que raro año hay en que no pasan de dos mil cabezas las que remiten de venta a los presidios de la línea, sin otros efectos como medias, frazadas y tejidos, acreditando así su laboriosa aplicación" (132). "Cerca del pueblo de El Paso del Norte hay otros cuatro [pueblos] de indios conocidos por los nombres de piros, mansos, julimes y tiguas que viven con la mayor sujeción a los ministros doctrineros y a la justicia ordinaria, aplicados a sus labranzas y en especial al cultivo de las viñas de que abundan aquellos terrenos..." (233). 
En la provincia de Tejas, O'Conor se refiere a los tehuacanes, ixcanis y taobayas como "a quienes principalmente se culpa de las irrupciones cometidas años pasados en el presidio de San Sabá, y no falta quien apoye haber sido provocados a ellas con opresiones y otros malos tratos." (235). De los comanches explica que son "nativos del dilatado país que encierran las cordilleras del Nuevo México y el caudaloso río Misuri. (...) Son diestros en el manejo del caballo y lanza, y de mucho tino en disparar flechas. Viven siempre bajo de tiendas, vagando de un lugar a otro, sin hacer más mansión que la que necesitan hasta que con la caza se proveen de ciervos y cíbolos de que sacan su alimento y vestuario" (237).

Pocos años antes del informe de O'Conor, el capitán Nicolás de Lafora había recorrido la frontera como ingeniero en el viaje de inspección del mariscal Rubín ${ }^{27}$. Dice Lafora en su diario que los indios apaches

"Varían poco en su idioma, nada en sus armas, que son arco y flecha; ni en la suma crueldad con que tratan a los vencidos, atenazándolos vivos y comiéndose la carne que les arrancan; flechándolos y, finalmente, ejecutando cuantas crueldades son imaginables, habiendo llegado repetidas veces el caso en la Nueva Vizcaya de abrir vivas la mujeres encintas y, sacándoles las criaturas, azotarlas con ellas hasta hacerlas expirar".

Las referencias de Lafora a la crueldad de los apaches están mezcladas con opiniones sobre otros aspectos de su cultura:

"Son sumamente holgazanes, poco o nada siembran, y así se ven precisados a robar para comer. Y siéndoles indiferente un pedazo de mula, de caballo o de venado, prefieren el ir en busca del primero, quitando las caballadas a los españoles porque con menos fatiga que cazando se aseguran el alimento con mayor abundancia; por eso, siempre han sido, son y serán perjudiciales a sus vecinos, estén de guerra, ya de paz...".

Siglos de enfrentamientos entre españoles e indios habían consolidado en la frontera prácticas universales como la toma de cautivos, la utilización del enemigo contra el enemigo, la paz y la sumisión mediante pactos y regalos o el incentivo del comercio. El Caballero de Croix, primer titular de la Comandancia General de las Provincias Internas, pretendía que la captura de mujeres y niños contribuyera a debilitar al enemigo y a la aculturación de los que pasaban a vivir con los españoles. Los apaches, a su vez, consideraban que los cautivos indios o españoles eran parte de su botín de guerra. Un expediente fechado en 30 de octubre de 1779 en el presidio del Norte informa del rescate de españoles que se hallaban en poder de los apaches. Aparece el nombre, el lugar

27. Lafora, Nicolás de, Relación del viaje que hizo a los presidios internos situados en la frontera de la América septentrional. Vito Alessio Robles, ed. Robledo. México, 1939. 
de donde proceden, y el caso de una mujer y dos muchachos apaches que se fugaron solicitando vivir con los españoles ${ }^{28}$.

Una de las decisiones de Croix fue cambiar el equilibrio de poderes mediante la alianza con los comanches y la ayuda de éstos contra los lipanes apaches. Esto le escribía el comandante general a Gálvez en uno de sus extensos informes generales redactados entre 1780 y 1782 :

"Guiados de sus malas características inclinaciones, y de la necesidad de robar para comer, porque los indios no saben otro modo de subsistir ni podemos mantener sus numerosas familias, ni satisfacer la codicia de sus impertinentes antojos, es preciso que los de paz hostilicen descubierta o encubiertamente, pero me parece que nunca pueden ser sus robos tan frecuentes como lo serían en guerra declarada. (...) Es axioma en el concepto general que si nuestras operaciones de guerra en estas provincias pudieran ser en todo semejantes a las de los indios, contaríamos con progresivas y seguras victorias, ¿pues por qué no hemos de procurar imitarlas en lo posible"29.

En 1787, el gobernado intendente Felipe Díaz Ortega "Manifiesta el infeliz estado en que se hallan los partidos de Chihuahua y los demás de aquella provincia por las incursiones, robos y muertes que ocasionan los indios; la decadencia del comercio y rentas reales y despueble que ya se experimenta de muchos pueblos. Todo lo cual acredita por los documentos testimoniados que acompaña". En el expediente hay, entre otros muchos documentos, dieciocho folios con 93 apartados, cada uno de los cuales incluye una o más unidades de explotación, todo ello bajo el título de "Apunte de los ranchos, estancias y labores despobladas por la opresión de los bárbaros apaches en las inmediaciones de Chihuahua". He aquí unos cuantos ejemplos tomados de un relato escrito en primera persona por alguien que conocía la situación de manera muy directa:

“1. Primeramente, el rancho que Ilaman del Salitre (...) de donde se llevaron los bárbaros apaches el ganado de los Jaboneros, que llamaban, que eran como quinientas reses, a las diez del día, pues lo vi con mis propios ojos, sin que hubiese quien les diera socorro. 2. El rancho de Jesús María, cría de ganado mayor y caballada, en donde alcancé a varios vecinos poblados en dicho rancho con sus pegujales de ganado y caballada; a éstos, los que no mataron los indios los dejaron imposibilitados y sin bienes. (...) 17. El valle entero de Casas Grandes despoblado, tan hermoso y tan útil para criar ganado y caballada, como para sembrar; tan amplio que infiero no tendrá la Vizcaya tierras más hermosas. En este valle alcancé muchísimos vecinos, todos muy ricos de bienes (...). 18. La estancia y

28. Expediente unido a carta de Croix a Gálvez, 30 octubre 1779. AGI, Audiencia de Guadalajara 271.

29. Croix a Gálvez, 23 abril 1782. AGI, Audiencia de Guadalajara 253. 
labor de San Miguel, que fue del difunto don Eugenio Ramírez. Alcancé un rodeo de ganado mayor, que era tanto que ya no les era posible herrar las crías ni contarse, muy hermoso. 36. La Laguna de Pacheco, perteneciente a don Antonio del Castillo, con un rodeo de ganado mayor de catorce mil y más reses, y cría de ganado menor, con un obraje muy hermoso, el cual todo lo han quemado los enemigos. 58. El rancho que fue de Bartolo de León. En este rancho alcancé al mencionado con veinte y cuatro manadas de yeguas y bastante ganado mayor, y no tan sólo acabaron los bárbaros con los bienes sino hasta con la vida de ellos. 60. Y en la sierra de las minas de Chihuahua había varios ranchitos, el pozo de Marques, el aguaje de San Juan. Los alcancé poblados de muchos yaquis y pimas; éstos se ejercitaban en pepenar metales plomosos, que hay por todas partes varias cintitas muy ricas en toda la sierra que Ilaman Chihuahua el Viejo, y todo lo han abandonado por los bárbaros apaches".

Tras el epígrafe 93 hay diez folios con otras muchas referencias a situaciones concretas y una descripción de las "crueldades" de los apaches:

“... pues no pueblan estas tierras otra cosa si no es enemigos por todas partes, pues según su rabiosa envidia que tienen con nosotros estos bárbaros infieles, no ha sido su fin más de acabar con todo, pues es tanta su rabia que no están libres ni aun las caballadas alzadas que llaman mesteñas, pues hasta éstas las espían en los aguajes al tiempo que bajan a beber agua y allí las van tumbando a jarazos sólo por hacer mal ${ }^{30}$. Las anatomías que hacen con los cautivos cristianos que llegan a caer a sus manos son tantas que causan compasión, pues éstos la primera diligencia que hacen con ellos es después de desnudarlos, en pelota y descalzos, los incorporan entre las caballadas que llevan, y hacerlos andar al parejo de los brutos, y los que no pueden ya de cansados los mancuernan con una bestia para que ésta los Ileve arrastrando hasta dar fin con sus vidas. A otros los cuelgan de un palo y a menudos pedazos les van con cuchillo arrancando sus carnes vivos, bailando sus mitotes, y a otros les sacan los ojos vivos y con rigor les hacen que anden hasta que caigan en los mayores despeñaderos. A otros los atan de pies y manos, y así atados los queman vivos, pues de esto he visto mucho en tantos cuerpos muertos en manos de ellos que he levantado" ${ }^{\prime \prime 1}$.

Diversas causas, no siempre imputables a los indios, provocaban de vez en cuando hambrunas. En 1785, don Juan Velázquez, gobernador interino de Nueva Vizcaya, da cuenta al comandante general de las Provincias Internas de un motín en el real de minas de Cuencamé provocado por el hambre. Las mujeres

30. Jarazo: golpe dado con la jara. Jara: palo de punta aguzada y endurecido al fuego, que se usaba como dardo.

31. Del expediente de Díaz Ortega a Valdés y Bazán, con testimonios, 6 diciembre 1787. AGI, Audiencia de Guadalajara 302. 
han tomado la iniciativa y su protesta pone de manifiesto no sólo la falta de alimentos sino de medios humanos y materiales para remediar la situación.

"Entre las aflicciones es de ver en el día esta ciudad [de Durango] amenazada de hambre, como azote que se padece en la mayor parte de toda la provincia, sin que alcance a su remedio el arbitrio humano; me hallo en el cuidado de estar amotinado el real de Cuencamé, cuyas mujeres han alzado el grito contra el alcalde mayor, y antes de que se saquen la cara los hombres que las seducen, he formado la adjunta Instrucción y con ella he despachado al comandante don José Ximénez Caro con la gente que se ha podido juntar y sólo doce lanzas, que son las únicas armas que se han adquirido para una empresa tan delicada; pero tocándose en el extremo de no haber ni una mula para transportar el bastimento, han marchado a pie, conduciéndose en burros las sillas y el previsto alimento hasta la hacienda de Santa Catarina, donde podrán adquirir algunos de los auxilios que en ésa están, para cuyo fin lleva el comandante órdenes preventivas; y le entregué antes de marchar el dinero necesario hasta fin del mes, quedando con el cuidado de disponer se le suministre el que necesite hasta concluir la expedición. Y como no permite la urgente necesidad esperar las órdenes de V. S. para sacar dinero de estas reales cajas, he determinado se saque a cuenta de mis sueldos, ínterin que V. S. me previene el modo de reintegrar estos gastos, resolviendo lo que fuere de su agrado" ${ }^{\prime \prime 2}$.

La alarma ha desaparecido pocos días después, y Velázquez tranquiliza al comandante general: "Por los partes sucesivos que me despacha el comandante don José Ximénez Caro, estoy fuera de cuidado en que me puso la sublevación del real de Cuencamé, 40 leguas N. E. de esta ciudad. Y su origen no fue falta de fidelidad al Rey, sino estrechados del hambre por el retardo de acopiar maíz $z^{\prime \prime 33}$.

\section{Reflexiones y comentarios}

La historia de la frontera norte de Nueva España fue un proceso de tres siglos a los que hay que sumar $-y$ tener en cuenta- sus antecedentes y consecuentes. La naturaleza había creado desde tiempo inmemorial una barrera entre la civilización y la barbarie. Acontecimientos políticos (como la guerra entre Estados Unidos y México) y movimientos sociales recientes no sólo han prolongado una situación de frontera sino que han hecho que la frontera sea más compleja y dinámica. Todavía en el siglo XVIII, nuevos "bárbaros" entraron en el Gran Norte o penetraron más adentro perpetuando el estado de guerra. La expansión de los Estados Unidos hacia el oeste en el siglo XIX no puso fin a la vieja frontera sino que dio comienzo a un creciente solapamiento de dos ramas de la civili-

32. Velázquez a Rengel, 30 abril 1785. AGI, Audiencia de Guadalajara 302.

33. Velázque a Rengel, 8 mayo 1785. AGI, Audiencia de Guadalajara 302. 
zación occidental: la hispana y la angloamericana. Esa frontera híbrida pervivirá por mucho tiempo pues sigue alimentándose de la corriente que hace cinco siglos puso rumbo norte y hoy corre más densa y fluida que nunca.

Los especialistas conocen bien la historia de la frontera norte y tienen respuestas, no sin discrepancias, a preguntas como las siguientes: ¿Fue la frontera norte un éxito o un fracaso, sobre todo si se compara con la conquista del Oeste? ¿Fue el Gran Norte un fenómeno singular o hubo en las Américas fronteras similares? ¿Qué y cuánto tuvieron en común esas fronteras y cuáles fueron sus diferencias? Si la Corona y la Iglesia tenían sus motivos para penetrar donde los aztecas nunca lo hicieron, ipor qué los simples vecinos españoles ocuparon unas regiones remotas cuando en el Nuevo Mundo había tierra de sobra, habitada por indios agricultores acostumbrados a la sumisión política y al tributo?

No ha pretendido este breve y modesto ensayo resumir y menos contribuir a la historia de la frontera norte ${ }^{34}$. El propósito ha sido ofrecer mediante unas pocas pinceladas la versión de algunos hechos que aparecen en escritos tan personales y espontáneos como las cartas que los españoles dirigían al rey o a su Consejo de Indias. Nadie mejor que los habitantes o los residentes temporales del Gran Norte puede describir lo que era la vida en la frontera, trasmitirnos en primera persona sensaciones y sentimientos íntimos. Estos testimonios son el complemento imprescindible a una historia política y de guerra que, ciertamente, tuvo como instituciones relevantes el presidio y la misión; pero sin olvidar, sino todo lo contrario, que los particulares o vecinos fueron también parte activa y pasiva del drama con una diferencia importante: los soldados y los misioneros tenían en el indio su razón de ser, incluido el riesgo asumido de morir en la empresa. Por el contrario, la existencia de los particulares se desarrollaba a pesar del indio ${ }^{35}$.

Cuando los textos de archivo son expresión directa y espontánea de sus autores, abundantes en número, variados y reiterativos en su contenido, es posible considerar a los que escriben como informantes de su propio pasado ${ }^{36}$. Esto justifica la transcripción literal de los testimonios que a modo de ejemplo han ilustrado este ensayo. El verdadero significado de las palabras hay que buscarlo en su tiempo y en su contexto sociocultural. Fuera de estos dos marcos, la misma palabra puede significar algo distinto, y la distorsión puede ser muy gra-

34. La obra más comprensiva y el mejor tratamiento del tema es Weber, D., The Spanish Frontier in North America. Yale University Press. New Haven y Londres, 1992. Edición en español, Fondo de Cultura Económica. México, 2000. Un tratamiento general en tiempo y espacio, con abundante documentación de archivo, en Jiménez Núñez, A., El Gran Norte de México.

35. Los vecinos, organizados en milicias, eran también llamados a las armas ocasionalmente pero este cuerpo de civiles fue en las Américas más simbólico que efectivo.

36. Véase a este respecto, Jiménez Núñez, A., "Sobre el concepto de etnohistoria". Primera Reunión de antropólogos españoles, (Jiménez Núñez, A. ed.), pp. 91-105. Universidad de SeviIla, 1975. Como bien sabemos, la fuente esencial de la etnohistoria o antropología histórica son los documentos de archivo. 
ve cuando hay traducción a otro idioma. Por esta razón hemos querido que hablen ellos ${ }^{37}$. Su visión puede no ser objetiva, pero es su visión. Sus cartas y testimonios suscitan preguntas y apuntan respuestas: ¿Qué pretendían y qué esperaban los vecinos de la Corona? ¿De qué se quejaban y con qué palabras expresaban sus lamentos? ¿Cómo veían y describían al indio? ¿Cómo afectaba la guerra a su economía? ¿Era la tierra estéril o rica? Decimos esto porque en la documentación no faltan opiniones contradictorias según tiempo, lugar o intereses personales. ¿Por qué vivían en remotas regiones bajo una firme e inescapable dependencia del poder real?

En un estado de permanente peligro y pobreza general, las demandas y quejas de los vecinos muestran un estado de ánimo dominado por lo que calificaban reiteradamente como desasosiego, aflicción, resignación... Es particularmente curiosa la alusión a las lágrimas, al Ilanto como prueba de sufrimiento: "En arroyos de lágrimas"; "continuas lágrimas y gemidos". Esto escribe en 1763 el coronel Ortiz Parrilla, capitán del presidio de San Sabá, en Tejas: "Las lágrimas de cuantos habitan las provincias internas no se enjugan y aquel país con gran trabajo se transita" ${ }^{\prime \prime 3}$. Parecería a primera vista que aquellos españoles carecían de las virtudes propias de una población de frontera como el individualismo, la independencia, la rebeldía, la entereza frente a las dificultades. ¿Eran cobardes, pusilánimes, irresolutos? Los informes y los partes de guerra están llenos de acciones de los vecinos ante los ataques de los indios. El padre Morfi, fino y crítico observador de la frontera, describe en su diario un hecho que suena a película del Oeste: "Longoria [dueño de un rancho en Coahuila] tuvo la gloria de que él solo, con la débil ayuda de su esposa, que le cargaba las armas, hizo frente a gran número de enemigos; mató dos y puso a los demás en precipitada fuga ${ }^{\prime \prime 3}$.

Desde la consideración tan española del monarca como padre, los vecinos se muestran como hijos desvalidos que todo lo esperan de la piedad y justicia de Su Majestad. Ni siquiera en los peores momentos, dejan de expresar su lealtad como fieles vasallos de la Corona. Su actitud es la misma ante la divinidad (la Providencia) en concordancia con una coherente cosmovisión. Todo se resume en rogar, suplicar, argumentar respetuosamente y esperar con paciencia la gracia o la merced de las dos majestades: Dios y el Rey. Las demandas, quejas o denuncias se edulcoran al final de los escritos con despedidas cuyo tenor se mantiene a través de los siglos. Son expresiones retóricas pero reflejo sincero de su pensamiento: "Nuestro Señor guarde y prospere la Católica, Cristiana, Real

37. "Que hablen ellos" es el título de la segunda parte de Jiménez Núñez, A., El Gran Norte de México.

38. Testimonio de autos. AGI, Audiencia de México 1933A.

39. Morfi, Agustín de, Diario y derrotero (1771-1781). Varias ediciones. La cita corresponde en el diario al día 16 de febrero de 1778. Morfi viajó como asesor y capellán de don Teodoro de Croix en su viaje por las provincias internas. Hay otros muchos casos en el diario de ingenio, laboriosidad y también desidia o indolencia de los españoles criollos o peninsulares. 
Majestad largos tiempos con mayores estados y reinos y acrecentamiento de ellos y vencimiento contra los infieles como estos leales vasallos de V. M. lo desean". También las autoridades civiles, militares o religiosas presentan esa actitud reverencial y sumisa pues no en vano comparten un mismo sistema de creencias. Pero esas autoridades eran más que simples vasallos. Ya fueran laicos o eclesiásticos, estaban sujetos por vocación a la autoridad que servían, lo que hacía más obligada su fidelidad y obediencia.

Unos últimos párrafos sobre el núcleo del tema que nos ocupa: el indio. No se podía esperar de unos nómadas cazadores otra cosa que la defensa a muerte de su territorio y el aprovechamiento de todo lo que favoreciera su libertad y su economía. De aquí su resistencia centenaria y, al mismo tiempo, la apropiación de nuevos elementos, principalmente el caballo y las armas de fuego proporcionadas por europeos rivales de España. El robo de ganado resultó asimismo más rentable que la tradicional caza del cíbolo u otros animales salvajes. Para el indio, aquello no era robo sino el ejercicio de una economía más eficiente y cómoda. Afirma Lafora que los apaches, "Son holgazanes, poco o nada siembran, y así se ven precisados a robar para comer". Dicho todo esto, la crueldad hasta extremos espeluznantes fue la norma contra los españoles. Una crueldad que entre los apaches tenía como principal motivación instalar el terror en los corazones de los vecinos y de los indios de paz. La descripción de un militar ilustrado como Lafora o la información que recoge el gobernador intendente Felipe Díaz Ortega superan todo lo imaginable.

Justo es decir también que no todos los indios infieles fueron crueles o tan crueles. Las mismas autoridades españolas destacan y diferencian la conducta en la guerra y en la paz de enemigos formidables como los comanches ${ }^{40}$. También merecieron elogios otros muchos indios por su laboriosidad, fidelidad, habilidad para los oficios y eficaz intervención en la guerra como "indios auxiliares". No estaba en la mente de los españoles la idea de que el indio fuera malo por ser indio. Los misioneros, en particular, hacían responsable al diablo de las maldades de los indios gentiles, razón de más para procurar su conversión y bautismo.

Hubo unanimidad entre los españoles de la frontera al señalar la guerra como causa de ruina y pobreza. Todas las actividades económicas se veían afectadas por la amenaza constante y los asaltos frecuentes, desde la minería a la ganadería, la agricultura o el comercio en todas sus escalas. No hay espacio ni es ocasión para las comparaciones pero el contraste del Gran Norte con el Gran Oeste aportaría luz y rebajaría prejuicios y menosprecios ${ }^{41}$. La historiografía

40. Véanse, por ejemplo, las inteligentes y ponderadas observaciones del teniente José Cortés en John, E. A. H., ed., Views from the Apache Frontier. Report on the Northern Provinces of New Spain by José Cortés, Lieutenant in the Royal Corps of Engineers, 1799. University of Oklahoma Press. Norman y Londres, 1998.

41. Véase, por ejemplo, Jiménez Núñez, A., El Gran Norte de México, capítulo nueve, especialmente pp. 453-472. 
norteamericana ha calificado tradicionalmente la frontera española como un fracaso, aludiendo al escaso grado de poblamiento y desarrollo económico, mientras que la expansión hacia el Pacífico (la conquista del Oeste) se ha magnificado hasta los niveles del mito. Fueron siglos distintos. EI XIX se aprovechó de los inventos de la Revolución Industrial. El ferrocarril y el telégrafo contribuyeron mucho a una expansión de todas formas admirable. No obstante, la guerra contra el indio perduró hasta los últimos años del siglo XIX a pesar de contar desde años antes con oficiales salidos de la Academia de Westpoint y con armas automáticas. Por el contrario, el ejército regular español nunca fue importante ni numeroso en las Américas porque los enemigos del imperio atacaban desde el mar. El Gran Norte contó con el presidio y el soldado presidial o de cuera, en muchos aspectos en inferioridad de condiciones respecto del indígena, que luchaba en su propio terreno, en pequeñas partidas, sorprendiendo y huyendo de inmediato a sus refugios.

Una última reflexión acorde con lo que ha sido leitmotiv de este ensayo. Hay que contemplar, nunca juzgar, a los vecinos españoles de la frontera norte bajo sus propias circunstancias de tiempo y cultura. La misma regla debe aplicarse a quienes un día se vieron sorprendidos en su propia tierra por gente extraña venida de otro mundo.

\section{Bibliografía}

CUTTER, Donald, ed. y trad., The Defenses of Northern New Spain. Hugo O'Conor's Report to Teodoro de Croix, July 22, 1777. Southern Methodist University Press. Dallas, 1994.

DEVEREUX, George y LOEB, Edwin, "Antagonistic acculturation", American Sociological Review 8 (1943), pp. 133-148.

JIMÉNEZ NÚÑEZ, Alfredo, "Sobre el concepto de etnohistoria". En Primera Reunión de antropólogos españoles, (Jiménez Núñez, A., ed.), pp. 91-105. Universidad de Sevilla, 1975.

- "El fenómeno de frontera y sus variables. Notas para una tipología". Estudios fronterizos 40 (1997), pp. 11-25.

- El Gran Norte de México. Una frontera imperial en la Nueva España (15401820). Editorial Tébar. Madrid, 2006.

- "El bárbaro en la mente y la voz del ilustrado: la frontera norte de Nueva España (s. XVIII)". En Bernabéu Albert, S. (coord.), El Gran Norte de México. CSIC. Madrid. En prensa.

JOHN, Elizabeth. A. H., ed., Views from the Apache Frontier. Report on the Northern Provinces of New Spain by José Cortés, Lieutenant in the Royal Corps of Engineers, 1799. University of Oklahoma Press. Norman y Londres, 1998.

LAFORA, Nicolás de, Relación del viaje que hizo a los presidios internos situados en la frontera de la América septentrional. Vito Alessio Robles, ed. Robledo. México, 1939. 
MIKSELL, Marvin "Comparative Studies in Frontier History". Annals of the Association of American Geographers 49 (1959), pp. 62-74.

WEBER, David J., The Spanish Frontier in North America. Yale University Press. New Haven y Londres, 1992.

- Bárbaros. Spaniards and their Savages in the Age of Enlightenment. Yale University Press. New Haven y Londres, 2005.

WEBER, D. y Rausch, Jane M., eds. Where cultures meet. Frontiers in Latin American History. Scholarly Resources Inc. Wilmington, Del., 1994. 
